\title{
Review on the role of geoelectrical surveys in characterizing and deriving the constraints and hydrogeological conditions in semi arid Khanasser Valley region in Syria
}

\author{
Jamal ASFAHANI \\ Atomic Energy Commission, P. O. Box 6091, Damascus, Syria \\ tel: +963116111926; fax: 963116112289, e-mail: cscientific@aec.org.sy
}

\begin{abstract}
This paper is a general review which basically focuses on the role of geoelectrical surveys in characterizing and deriving the constraints and hydrogeological conditions in semi arid Khanasser valley region and its surroundings in Northern Syria. Schlumberger configuration has been used to carry out ninety six vertical electrical soundings VES, distributed on nine transverse and three longitudinal profiles. Their quantitative 1D interpretations with different techniques yield to develop several alternative approaches, that enable us to derive and determine the hydrological parameters of the structures controlled by the groundwater distributions. Two different northern and southern geological structures separated by Hobs-Serdah water divided line were electrically characterized. Both of them are of very conductive zones of a resistivity less than $4 \Omega \mathrm{m}$, and related to the intrusion of salty water in Quaternary and Paleogene aquifers. The qualitative interpretation of the iso-apparent resistivity maps for different $A B / 2$ spacings has allowed the delineation of those two structures. Those two identified structures have their evident influences on the distributions of thicknesses, resistivity, salinity, hydraulic conductivity, and transmissivity of both Quaternary and Paleogene aquifers. The high resistivity exceeding $300 \Omega \mathrm{m}$ on the measured VES is a very good signal of the presence of basalt formation of upper Miocene age in Jebel Al Hass in the west and Jebel Shbith in the east. The geometry and the electrical characteristics of Quaternary and Paleogene aquifers and the top of Maestrichtian have been well recognized. Quaternary paleosabkhas, fractured zones and tectonic features of the subsurface of Khanasser valley have been delineated through analyzing VES distributions along the executed longitudinal and transverse profiles. Different empirical relationships have been already established through coupling geoelectrical resistivity and hydrochemical data, which allows to derive and establish different salinity maps for different $A B / 2$ spacings, and to outline the boundaries between fresh, brackish and saline waters. Two different alternative approaches have been also developed for geophysically computing and estimating the hydraulic conductivity and the transmissivity of the aquifers in the study region. The different hydrogeophysical approaches developed in this integrated geophysical research project for water resource management have been successfully applied in Khanasser valley, and can be recommended to be practiced in similar worldwide areas.
\end{abstract}


Key words: electrical resistivity methods, hydrogeology, semi-arid regions, Khanasser valley, Syria

\section{Introduction}

The growing population problem and the development projects lead to increasing demand for groundwater as a national target. The application of very severe water management practical laws, however, have the ability to improve water quality and its use. Hydrogeological modeling procedure is a useful practice tool for water conservation and tables protection (JaworskaSzule, 2009; Takhur, 2016), but sufficient details about groundwater quantity, quality and movements are required for its successful application. We cannot unfortunately use the boreholes of prohibitive coast to get a precise hydrogeological schema. The relevant solution is therefore to incorporate the geophysical measurements to allow and elaborate such an hydrogeological procedure.

The DC geoelectrical methods are considered as primary geophysical tools, that play a dominant role in groundwater exploration. In fact, the resistivity parameter is intrinsic in such water researches, and more controlled by the water-related attributes than by the resistivity value of solid rock. A subsurface sedimentary layer could be often subdivided into distinct geoelectrical units depending on the water content and the degree of salinity. Moreover, different empirical and semi empirical relationships have been already developed between the resistivity $(\rho)$ and hydraulic conductivity $(K)$ of an aquifer (Chandra et al., 2008; Niwas and Singhal, 1985; Niwas and Singhal, 1981; Heigold et al., 1979; Kelly, 1977). Different power empirical law equations have been thereafter constructed between the different aquifer parameters and those obtained by geoelectrical resistivity techniques (Massoud et al., 2010; Attwa et al., 2009; Soupios et al., 2007; Purvance and Andericevic, 2000; Arétouyap et al., 2015, 2017, 2018; Tizro et al., 2010, 2012; Kazakis et al., 2016; Niwas et al., 2011; Niwas and Celik, 2012).

Apparent resistivity measurements $(\rho a)$ obtained through application of the geoelectrical (DC) methods are used to derive the resistivity distribution in the subsurface medium. The field resistivity data are quantitatively interpreted, where different possible solutions could by obtained by the inversion methods. The only inversed acceptable solution model is the one, 
which produces the best fit between measured apparent resistivity data and theoretical generated curve. The 1D inversed layered model is assumed while interpreting the vertical electrical sounding (VES), if the subsurface is basically $1 \mathrm{D}$ in the vicinity of the sounding location, and if the perturbations due to shallow lateral inhomogeneities are minimal. The 1D inversion practiced in this research for interpreting the field VES resistivity data has given quite reasonable results regarding the evaluated depths of geological interfaces in the study region. The VES technique is therefore still common and largely used for deep groundwater exploration problems, especially in semi-arid areas (Skinner and Heinson, 2004; Asfahani, 2007a; Asfahani, 2010a; Chandra et al., 2010; Eleraki et al., 2010; Khalil, 2012; Metwaly et al., 2012).

The study area is one of the integrated research sites of International Centre for Agriculture in Arid Dry Areas (ICARDA) National Resource Management Program. The choosing of this site is justified by addressing problems attached to the marginal dry land environments. The poverty and the relative easy accessibility, the diversity and dynamics of the natural resources and livelihoods, make the study region of Khanasser valley as a suitable prime candidate. The scientific program in this site includes regular monitoring of ground water levels and water chemistry, water use assessment, recharge studies, pumping tests, and geoelectrical investigation surveys. All those mentioned applied techniques in this project are oriented towards providing information for the formulation of sustainable resource management strategies and determining potential ground-water use. It is a fruit of collaboration between three scientific organizations, Syrian Atomic Energy Commission (AECS), ICARDA, and Bonn University, Germany.

This paper represents a general review that describes, summarizes and concentrates on the applications of the geoelectrical VES technique for solving different hydrogeological problems encountered in the semi arid regions such as Khanasser valley, Northern Syria (Fig. 1). This review paper aimed therefore at clarifying the integrated geoelectrical results that we have already obtained during the realization of this above project. The interested readers however are advised to consult our different cited papers in order to get more detailed information about all the different technical approaches discussed in this present review. The ten specific cited related papers, treating the different developed approaches, have discussed in more details all 


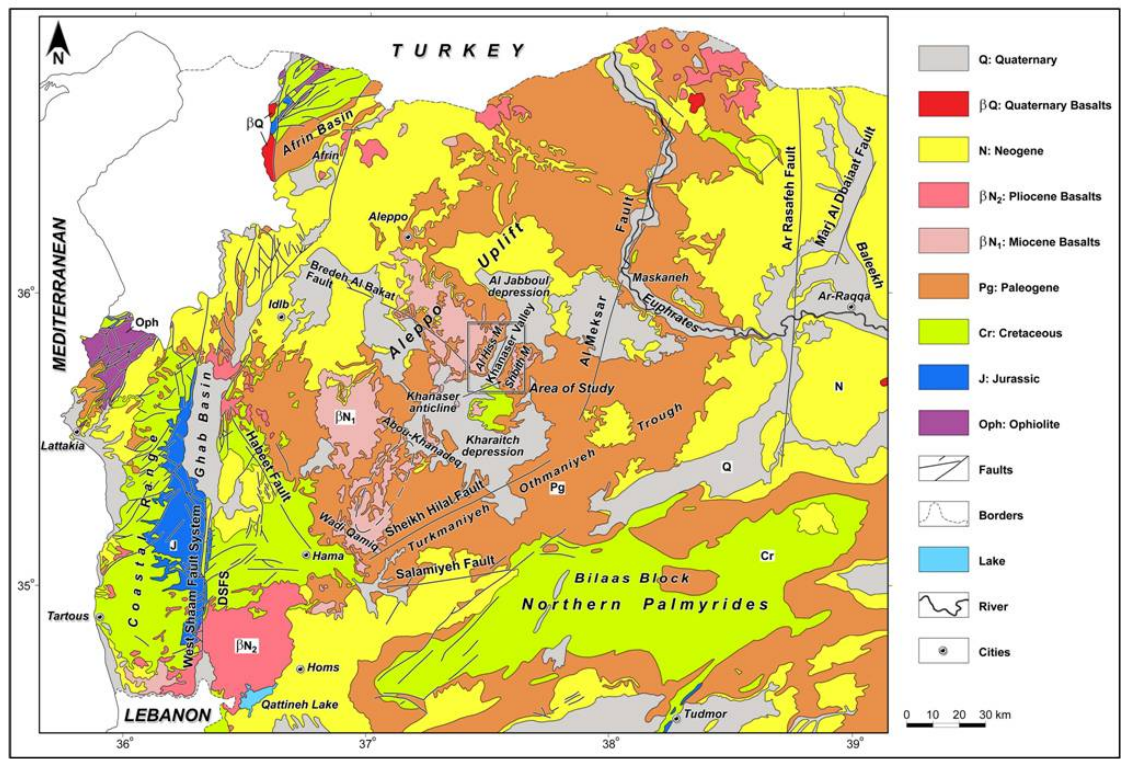

Fig. 1. Location of the Khanasser valley, Northern Syria and its geology.

the technical aspects related to the assumptions and interpretations.

The main objectives of the geoelectrical surveys carried out in Khanasser valley and its surroundings are therefore to cover the following geophysical research topics:

1. Determine the geometrical characteristics of both Quaternary and Paleogene aquifers in the Khanasser valley, and basalt of Al-Hess and Shbith mountains.

2. Clarify the tectonic and evolution scenario characteristics of the study area, especially the geological structures related with groundwater distribution.

3. Relate the geoelectrical resistivity data with aquifer hydrogeological parameters and transfer the measured resistivity maps to subsurface salinity and groundwater quality maps.

4. Evaluate the salt water intrusion phenomenon in the studied Khanasser valley region.

5. Determine the groundwater flow directions in the Quaternary and Pale- 
ogene aquifers in the Khanasser valley by using circular multi directional VES.

6. Develop and apply purely alternative geophysical approaches for deriving the hydraulic parameters of the aquifers in the study area.

\section{Geology and Hydrogeology}

Khanasser Valley of north-south direction is located in Northern Syria, approximately $70 \mathrm{~km}$ southeast of Aleppo city, and directly south of the salt lake of Jaboul. It is located $300-400 \mathrm{~m}$ above sea level, between the hill ranges of Jebel Al Hass in the west and of Jebel Shbith in the east as indicated on the Khanasser valley geological map (Fig. 1). The Maestrichtian "Cr2m", is the oldest formation in the area, and considered as a waterconfining layer of 150-200 $\mathrm{m}$ thickness (Ponikarov, 1964). The lithological outcrops of the study Khanasser valley consist of clay, clayey limestone flints, marl. The phosphate interbeds are observed in the southern part of the valley region.

The maximum thickness of the Paleogene formation "Pg", situated on the top of Maestrichtian, is more than $220 \mathrm{~m}$. It consists of clayey, chalky limestones and silicified limestones, related to Lower Eocene and the Middle Eocene formations (Ponikarov, 1964). Localized aquifers with low productivity are contained in both the middle and the lower Eocene (ACSAD, 1984).

On the top of the Paleogene rock, the Upper Miocene basalts, "BN1,3", are located and found in the west on Jebel Al Hass, and in the east on Jebel Shbith. These basaltic formations of an average thickness of $10 \mathrm{~m}$, and a maximum of more than $40 \mathrm{~m}$ do not contain ground-water resources in the Khanasser valley.

The Quaternary deposit of more than $25 \mathrm{~m}$ thickness exists in the centre of the valley, and consists of alluvial and lacustrine, proluvial, deposits. We can also find the gypsum in the lacustrine deposits. The Quaternary formation holds unconfined ground water in conglobreccia and sometimes in sand.

The semi-arid conditions dominate the valley, located at the fringe of the Syrian steppe (Hoogeveen and Zobisch, 1999). The valley is characterized 
by an annual rainfall of 200-250 $\mathrm{mm}$, with high annual and inter-annual variability (Soumi, 1991). The total surface of the study Khanasser valley is $322.5 \mathrm{~km}^{2}$. The Khanasser valley is composed of a gently undulating plain with a wide shallow network dry erosion channels. The hill ranges of Jebel Shbith and Jebel Al Hass form calm rolling plateaus, which end in welldefined steep scarps towards the Khanasser valley with V-shaped erosion channels.

Hydrologically, Khanasser Valley is located on the border between two surface water catchments (Wolfahrt, 1966, 1967; Hoogeveen and Zobisch, 1999). The surface water drains towards a salt depression (Sabkha) in the southern part of the steppe catchment. The Jaboul catchment is related to the northern part, in which the drainage pattern is directed towards the Jaboul salt lake. Those two basins are separated by a dividing line between Al Hobs and Serdah villages (Fig. 2).

The scarcity and the salinity of water resources increasing from south to north are regarded as the main serious obstacle in the development of the Khanasser study region.

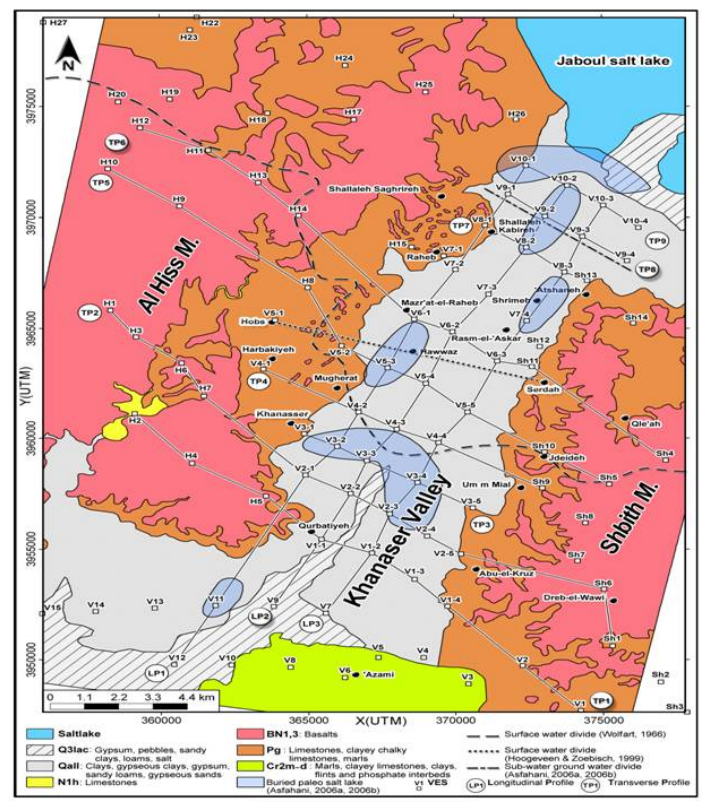

Fig. 2. Locations of the field VES in the Khanasser valley and its surroundings. 


\section{Geoelectrical Resistivity Field Surveys}

Geoelectrical surveys have been applied in the Khanasser valley and its suroundings to electrically characterise the behaviour of both Quaternary and Paleogeane aquifers in lateral and vertical directions. Vertical electrical resistivity sounding (VES) is the main geoelectrical technique applied in this research.

\section{Vertical Electrical Soundings (VES):}

The vertical electrical resistivity variations of the subsurface formations in the Khanasser valley have been studied and characterized by applying the Vertical Electrical Sounding (VES) technique. Ninety six VES with a Schlumberger configuration have been measured in the Khanasser valley and its surroundings. The locations of those VES are shown on Fig. 2.

The two $A$ and $B$ electrodes in the applied Schlumberger configuration are used to impose the electrical current $I$ on the study area, at varying spacing expanding symmetrically from a central point. The maximum distance between $A$ and $B$ of $1000 \mathrm{~m}(A B / 2=500 \mathrm{~m})$ has been adapted for all the VES carried out in the Khanasser study region. An additional pair of electrodes $M$ and $N$ at appropriate spacing are used to measure at the surface the resulting potential field $\Delta V$.

The field apparent resistivity $(\rho a)$ obtained by applying Schlumberger array is given by the following equation:

$$
\rho a=\frac{2 \pi}{\frac{1}{A M}-\frac{1}{B M}-\frac{1}{A N}+\frac{1}{B N}} \frac{\Delta V}{I},
$$

where $I$ is the current introduced into the earth, $\Delta V$ is the potential measured between the potential electrodes. $A M, B M, A N$, and $B N$ are the distances between the different current and potential electrodes.

The resistance $\Delta V / I$ is directly measured with an Indian equipment (ACR-1), which allows to obtain subsequently the apparent resistivity $(\rho a)$ according to Eq. (1) (Dobrin, 1976).

The VES technique is based on the reality that the fraction of current injected into the ground penetrating below a given depth, increases with augmenting successively the separation between the electrical current $A$ 
and $B$ electrodes. By such a VES procedure, the electrical resistivity variation with the depth below a given point on the earth surface could be easily obtained and estimated. Thus the electrical potential distribution on the surface of the earth will be affected relatively more by deep-lying inhomogeneities within the earth.

The increase of the electrode spacing $A B / 2$ about a fixed point, allows to successively establish the apparent field resistivity curve " $\rho a$ " as a function of $A B / 2$. The established field resistivity curves will be used for qualitative and quantitative interpretations as will be documented and explained in this paper.

Curve matching technique with the use of master curves (Orellana and Mooney, 1966) is applied and practiced to interpret the resulting field resistivity curves " $\rho a$ ", and to get the initial determination of thicknesses and resistivities of corresponding layers (initial approximate model). Inverse technique program is thereafter used to accurately interpret the parameters of the approximate model, until a goodness of fit between the field apparent resistivity curve and the regenerated computed curve is obtained (Zohdy and Bisdorf, 1989; Zohdy, 1989). A grid comprising nine transverse profiles oriented approximately NW-SE (Fig. 2), labelled $T P 1, T P 2, \ldots, T P 9$, and three longitudinal profiles $(L P 1, L P 2$ and $L P 3)$ has been designed to distribute the ninety six VES measured in the Khanasser valley. The distance between profiles was approximately $1 \mathrm{~km}$ and a VES was generally made every kilometer long each profile (especially in the valley itself). This observation interval was sometimes changed according to the topographic conditions (Asfahani, 200\%).

\section{Results and Discussion}

The Quaternary and Paleogene aquiferes have been described and characterized in details by conducting an integrated geoelectrical research in the study Khanasser valley, Northern Syria. The application of the geoelectrical technique is aimed at solving different hydrogeological problems, posed in the study area. Ninety six vertical electrical soundings (VES) have been therefore executed and measured in the Khanasser valley and its suroundings. The qualitative and quantitative interpretations of those 96 VES allow 
us to reach several important hydrological results at two qualitative and quantitative levels as follows:

At qualitative level, the analysis and the study of the iso-apparent resistivity lines corresponding to different spacings $A B / 2$ (from $3 \mathrm{~m}$ to $500 \mathrm{~m}$ ) reveals essentially the presence of two hydro-geological structures. One is located in the north and the other one is located in the south in the Khanasser valley region. Those two identified structures are separated by joining line of Hobs and Serdah, where a clear deep tectonic effect is present along this joining line (Asfahani, 200\%b).

The northern structure, which is an elongated conductive zone of $\mathrm{N} 36^{\circ} \mathrm{E}$ direction with a very low resistivity (less than $4 \Omega \mathrm{m}$ ) is the expression of saline groundwater intrusion in the Quaternary and Paleogene deposits. The same direction of $\mathrm{N} 36^{\circ} \mathrm{E}$ is remain kept for all the studied $A B / 2$ spacings, which obviously indicates to the hydraulic connection between Quaternary and Paleogene in this northern structure.

The southern structure is also an elongated conductive zone of $\mathrm{N} 62^{\circ} \mathrm{E}$, direction with also a very low resistivity (less than $4 \Omega \mathrm{m}$ ), due to the saline groundwater intrusion in Quaternary and Paleogene deposits (Asfahani, 200\%b). In this southern structure, a clear separation between Quaternary and Paleogene is signalled. In fact, this result is confirmed and sustained by the fact that the axis of the conductive zone related to the Paleogene deposit becomes perpendicular to that of Quaternary at $A B / 2$ spacings above $150 \mathrm{~m}$. In addition, the dimensions of the southern structure attenuate at $A B / 2$ spacings greater than $200 \mathrm{~m}$. A composite model of the spatial evolution of the two identified north and south structures is shown in Fig. 3 for $A B / 2$ of $70,100,150$, and $200 \mathrm{~m}$.

At quantitative level, the assumption of one-dimensional layered models $1 \mathrm{D}$ is taken into consideration in this research. Curve matching technique with its master curves are used to determine an approximate model including resistivities and thickness of coresponding layers. An inverse technique program (Resist software) is thereafter used to invert this approximated model and to get the final optimum solution model. A typical field example of VES curve at VES points 10-4 and its quantitative 1D interpretation model is shown in Fig. 4.

The inversed interpretative VES results are calibrated in this research 


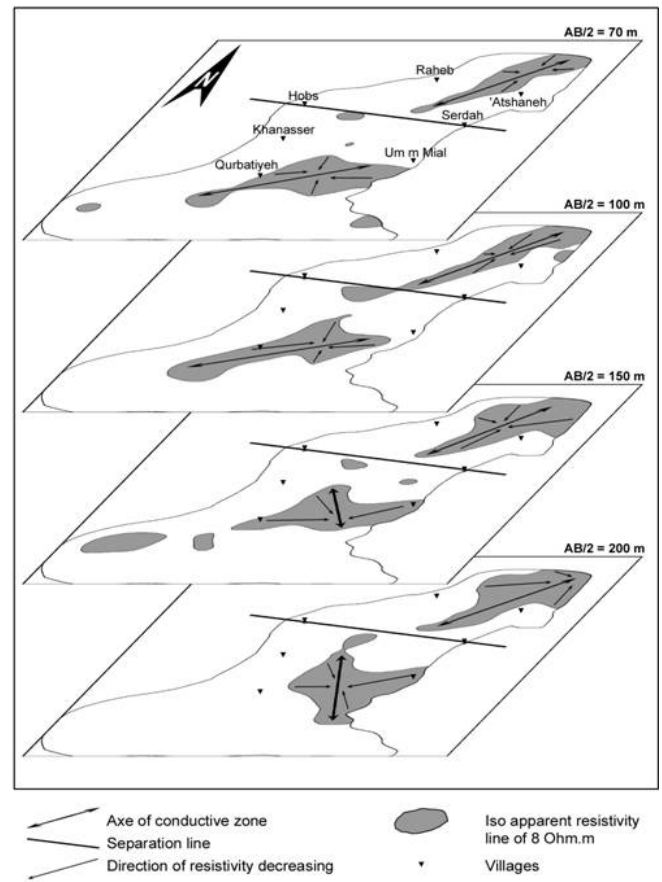

Fig. 3. Composite model for the two northern and southern structures for $A B / 2$ of 70 , 100, 150, and $200 \mathrm{~m}$ in the Khanasser valley (Asfahani, 2007b).

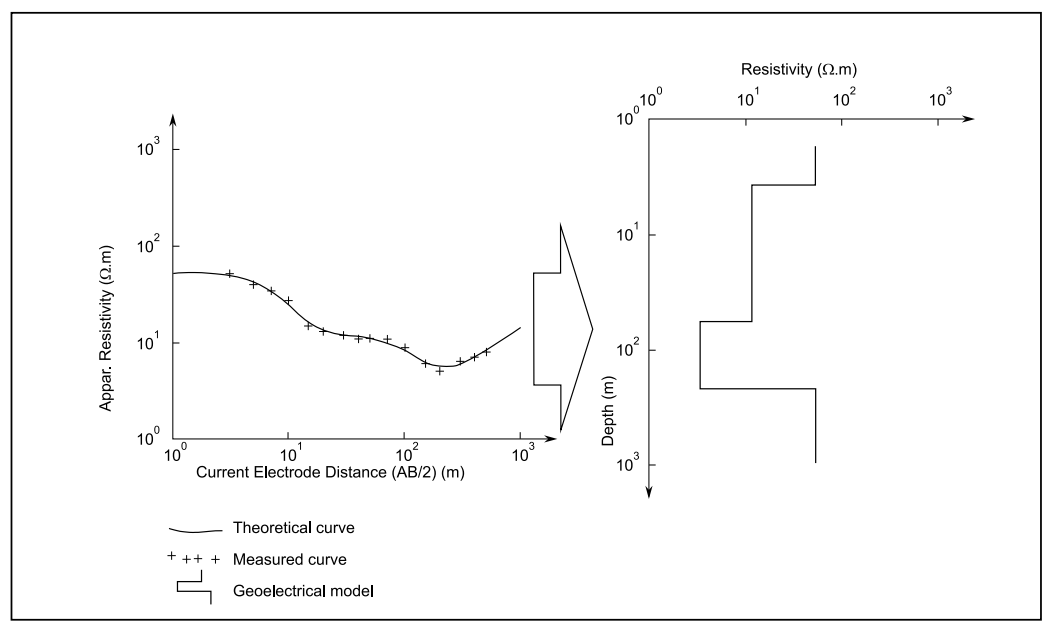

Fig. 4. Field VES at VES point 10-4 with its 1D quantitative interpretation (Asfahani, $2007 b)$. 
through:

- Geoelectrical response acquired of different formations surface outcrops. Each geological formation is characterized by a range of resistivity response, that must be geostatisticaly treated in order to be considered as an electrical signature for that formation. This procedure helps in delineating the subsurface extension.

- Geological cross-sections constructed from the available geological map of the area, that we compare and integrate with the obtained VES interpretation to establish a trustable subsurface image.

We could not use the available drilled wells in the study area as a source of information for the calibration, because they are of very shallow depth $(<70 \mathrm{~m})$ and have no lithological description logs.

The 1D VES interpretative results obtained in this integrated geophysical research allow to solve different hydrogeological problems in the Khanasser valley as follows:

1) Determine the geometrical characteristics of both Quaternary and Paleogene aquifers in Khanasser valley. The Quaternary aquifer thickness varies between a minimum of $4.5 \mathrm{~m}$ at the VES V4-3 $(3.3 \mathrm{~km}$ east of Khanasser) and a maximum of $99.4 \mathrm{~m}$ at the VES V9-2, $1.9 \mathrm{~km}$ northeast of Shallaleh Kabireh, with an average of $38.5 \mathrm{~m}$. Its resistivity varies between $4.1 \Omega \mathrm{m}$ and $43 \Omega \mathrm{m}$, with an average of $15.3 \Omega \mathrm{m}$ (Asfahani, 2007b). The Paleogene thickness varies between a minimum of $54 \mathrm{~m}$ at VES V11 and a maximum of $283 \mathrm{~m}$ at VES V4-3, with an average of $162.4 \mathrm{~m}$. Its resistivity varies between $1.7 \Omega \mathrm{m}$ and $16 \Omega \mathrm{m}$, with an average of $5.1 \Omega \mathrm{m}$ (Asfahani, 2007b).

The top of Maestrichtian is also established. It varies between a minimum of $60.2 \mathrm{~m}$ at VES V1 and a maximum of $353.5 \mathrm{~m}$ at VES V4-4, with an average of $193.7 \mathrm{~m}$. Its resistivity varies between $16 \Omega \mathrm{m}$ and $113 \Omega \mathrm{m}$, with an average of $49 \Omega \mathrm{m}$. The high resistivity of the Maestrichtian formation signaled at few locations in the study region (order of $110 \Omega \mathrm{m}$ ) is due probably to the presence of phosphate.

The influence of Basalt formation on the established iso-apparent resistivity maps is very well pronounced, enabling to eaisly trace and follow the boundaries of this formation, particularly in Jebel Al Hass. From the different iso-apparent resistivity maps, it is evident that basalt formation 
goes down deeply. Basalt thickness in Al Hass varies between $19 \mathrm{~m}$ and $95.5 \mathrm{~m}$, with an average of $51 \mathrm{~m}$, and basalt resistivity varies between $159 \Omega \mathrm{m}$ and $804 \Omega \mathrm{m}$, with an average of $380 \Omega \mathrm{m}$. The thickness of basalt in Jebel Shbith varies between $29 \mathrm{~m}$ and $61 \mathrm{~m}$, with an average of $44 \mathrm{~m}$, while its resistivity varies between $110 \Omega \mathrm{m}$ and $241 \Omega \mathrm{m}$, with an average of $166 \Omega \mathrm{m}$ (Asfahani, 2007b).

Fig. 5 ( $\mathrm{a}$ and $\mathrm{b}$ ) shows the variations of both thickness and resistivity of Quaternary, Paleogene and basalt along the longitudinal LP1 and the transverse TP5 profiles.

a) Subsurface geoelectrical model along the profile LP1.
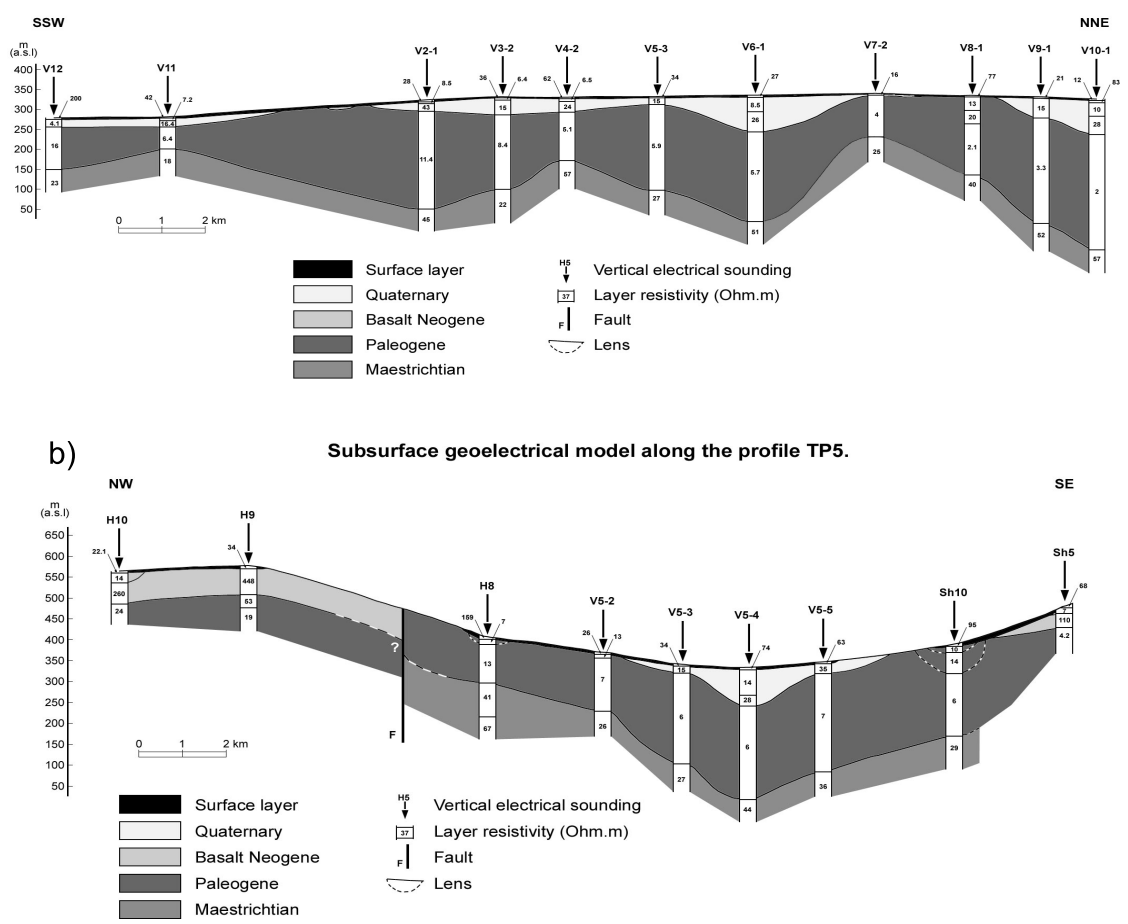

Fig. 5. Geoelectrical sections along LP1 (a) and TP5 (b) profiles (Asfahani, 2007b).

2) Pichgin and Habibullaev technique (see Pichgin and Habibullaev, 1985), which has been already modified and improved by Asfahani and Radwan (2007) is widely used in this integrated geoelectrical research to 
interpret the VES data distributed along the studied longitudinal and transverse profiles. It enables to precisely define the subsurface structures and the fracured zones by using the concept of non homogeneity points "+", whose distributions reflect them strongly. The twelve executed transverse and longitudinal VES profiles have been interpreted by this technique, where interesting subsurface tectonic features have been imaged and delineated. Figs. 6 (a, b, c) and Fig. 7 show examples of using this technique for interpreting LP2, TP1, TP6 and TP8 profiles. The integral geophysical-tectonic interpretation of those profiles allows to determine the tectonic and evolution scenario characteristics of the study Khanasser valley region, especially the geological structures related with groundwater distribution. A reliable, fast, and economical approach applicable in arid areas of prominent relief and topography in dry areas has also been proposed to detect subsurface structures hence locating favorable and promising sites to drill fresh groundwater wells (Asfahani and Radwan, 200\%). The valley was developed as a differentially subsiding graben during Quaternary and served temporarily as Paleo-Euphrates' course.The differential subsidence of the Khanasser graben's blocks formed characteristic structures of sharp rough morphology, smoothed later by the Paleo-Euphrates running water effect. This Khanasser graben became a greater lake extending from Al Jabboul depression to Kharaitch depression. The large paleo lake shrank gradually to its current borders, leaving behind the buried paleo salt lakes, whose locations and extensions fit very well with subsurface structures mapped by Asfahani (2007b), Asfahani and Radwan (2007) (Fig. 2).

The mapped subsurface horst structure groundwater divide, delineated at the center of Khanasser valley along the transverse TP8 profile (Fig. 7) separates between the northern and southern structures. The northern one is a deeper low structure, open to the Al Jabboul salt lake with more saline water due to a southward subsurface flow. The southern one is a shallower structure with saline, brackish and fresh water, which might be explained by local dilutions caused by a runoff percolation through dense faulting networks, (Fig. 7). The groundwater divide line determined already by Asfahani (2007b), is close to the surface water divide already delineated by Hoogveen and Zobisch (1999) rather than to that suggested by Wolfahrt (1966), to the south near Khanasser town. 
a)

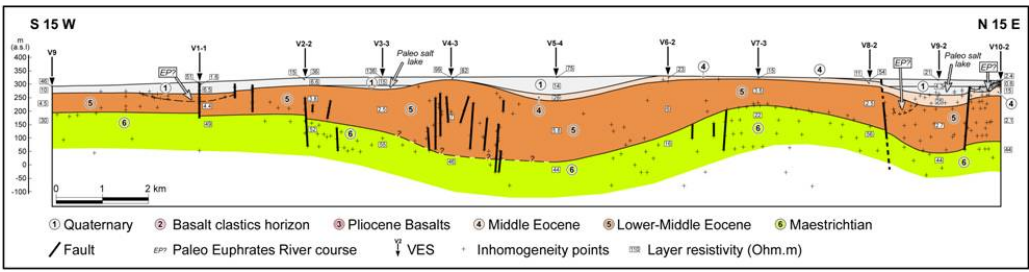

b)

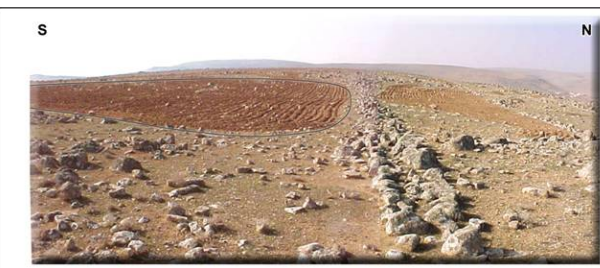

Cultivated maar sediments of the Qurbatiyeh volcanic crater

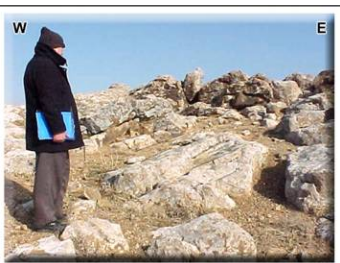

Inclined layered basalt at the rims of the Qurbatiyeh volcanic crater.

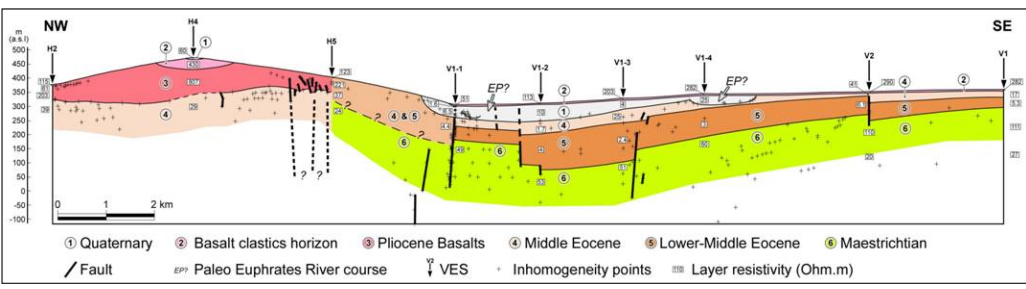

c)
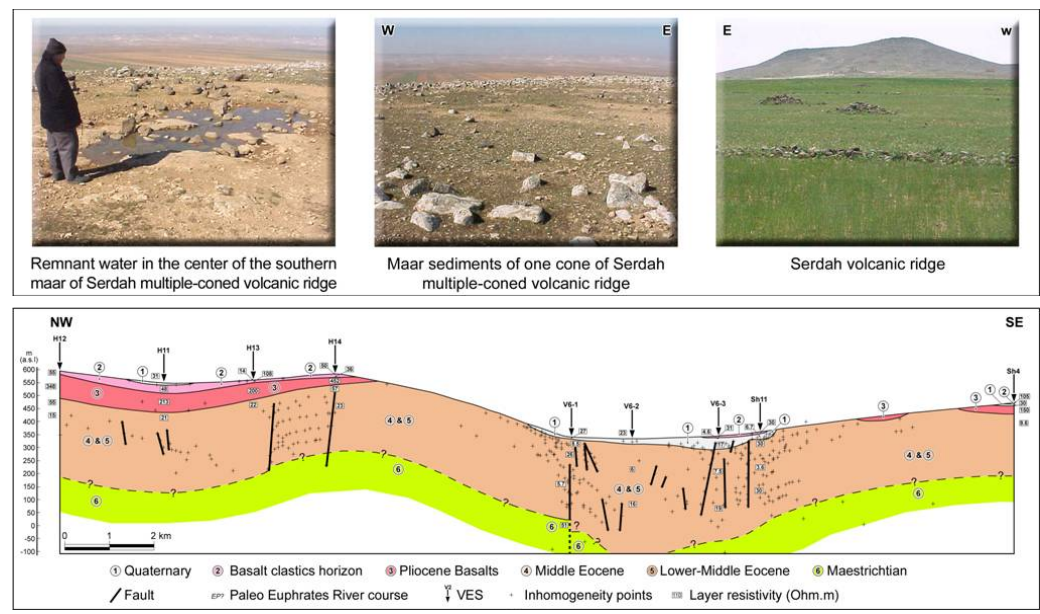

Fig. 6. Geoelectrical sections along LP2 (a), TP1 (b) and TP6 (c) profiles, derived by Pichgin technique (Asfahani and Radwan, 2007). 
Ground water flowed from this subsurface divide in the NNE direction toward the Al Jabboul depression and in the SSW direction toward the Kharaitch depression, as mentioned by Asfahani (2007b).

The tectonic-oriented interpretation of the mentioned twelve profiles, explains the origin of the Khanaser Valley as N15_E deep normal faults, formed by the $\mathrm{E}-\mathrm{W}$ tension which dominates in the northernmost parts of the Arabian plate. Those deep faults served as basaltic lava conduits before developing into a graben, whose central dissected blocks underwent a differential subsiding. The role of those dense faulting within the Khanasser Valley in mixing saline and fresh water is not excluded. Sulfuric water encountered in some wells drilled in the Khansser Valley may be attributed to the partial percolation of rainfall surface run-off, through bituminous chalky limestone middle Eocene intercalating levels.

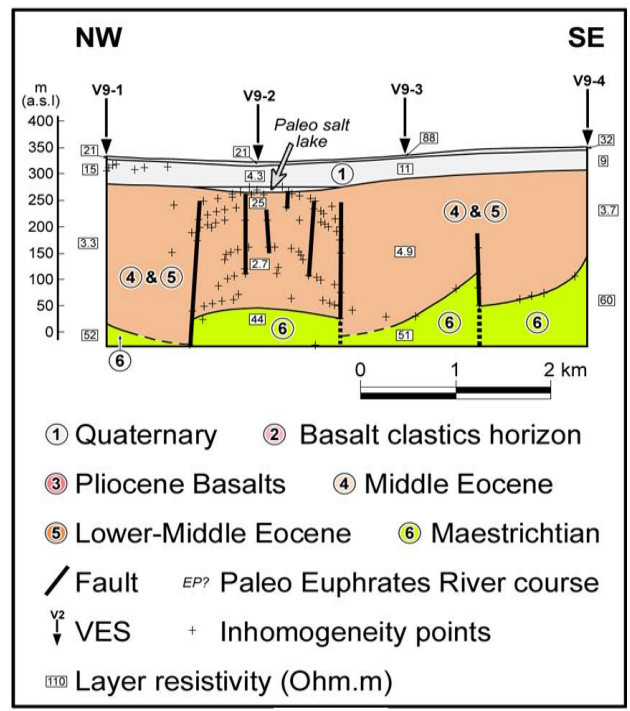

Fig. 7. Geoelectrical horst section along TP8 profile, derived by Pichgin technique (Asfahani and Radwan, 2007).

3) The second concern in this hydrogeophysical investigation in the Khanasser valley is to attach the measured geoelectrical resistivity data with the aquifer hydrogeological parameters in order to transfer the established resistivity maps to subsurface groundwater quality and salinity map. The conductivity $(\sigma w)$ and the TDS of well-water samples exist at the vicinity 
of some VES locations are calibrated together with the earth resistivities estimated from VES sounding. This is done to get empirical relationships between earth resistivity and water resistivity, and subsequently between earth resistivity and total dissolved solids (TDS), (Asfahani, 200\%c).

Regression analysis applied on such hydrogeophysical data indicates the following empirical relationship between earth resistivity and TDS concentration.

$\rho e=-0.0028 T D S+15.237$.

According to this empirical relationship, the iso-resistivity lines of 5, 10 and $15 \Omega \mathrm{m}$ represent a salinity of 2844,1935 and 1025 ppm respectively, (Asfahani, 2007c). It is worth mentioning that the earth resistivity values resulting from VES interpretation are representative of the Quaternary saturated zone, where the real resistivity layer corresponding to water sampling depth location was taken.

This calibrated regression relationship is used to convert the isoapparent resistivity maps corresponding for $A B / 2$ of 70,100 and $150 \mathrm{~m}$ into salinity maps. The obtained salinity maps corresponding to penetration depths of 70, 100 and $150 \mathrm{~m}$ clearly indicate the presence of the two mentioned geological structures trending of $\mathrm{N} 36^{\circ} \mathrm{E}$ and $\mathrm{N} 62^{\circ} \mathrm{E}$. Fig. 8a shows an example of the salinity map obtained in the Khanasser valley for a constant $A B / 2$ of $100 \mathrm{~m}$, for which the distribution of iso-saline lines clearly indicates the directions of water movement in the study region of Khanasser Valley.

Fig. $8 \mathrm{~b}$ shows the cross sectioanl variations of the salinity along the longitudinal profile LP3 as a function of $A B / 2$ (Asfahani, 2010b). The iso-TDS countours have tendancy to be allongated and directed towards the surface between V1-2 and V3-4 in the high TDS region, due to the excessive fresh water depletion in this area. The quality of groundwater is affected by such a depletion and by the ascent of saline ground water deep flow, that must be avoided. The positions of the faults shown in the Fig. 8b are determined through interpreting VES data distributed along LP3 by Pichgin and Habibuleave technique described above (Asfahani, 2010b).

The distribution of fresh ( $\rho$ e between 10 and $15 \Omega \mathrm{m}$ ), brackish ( $\rho$ e between 5 and $10 \Omega \mathrm{m}$ ) and salt water zones $(\rho e<5 \Omega \mathrm{m})$, and their 
a)

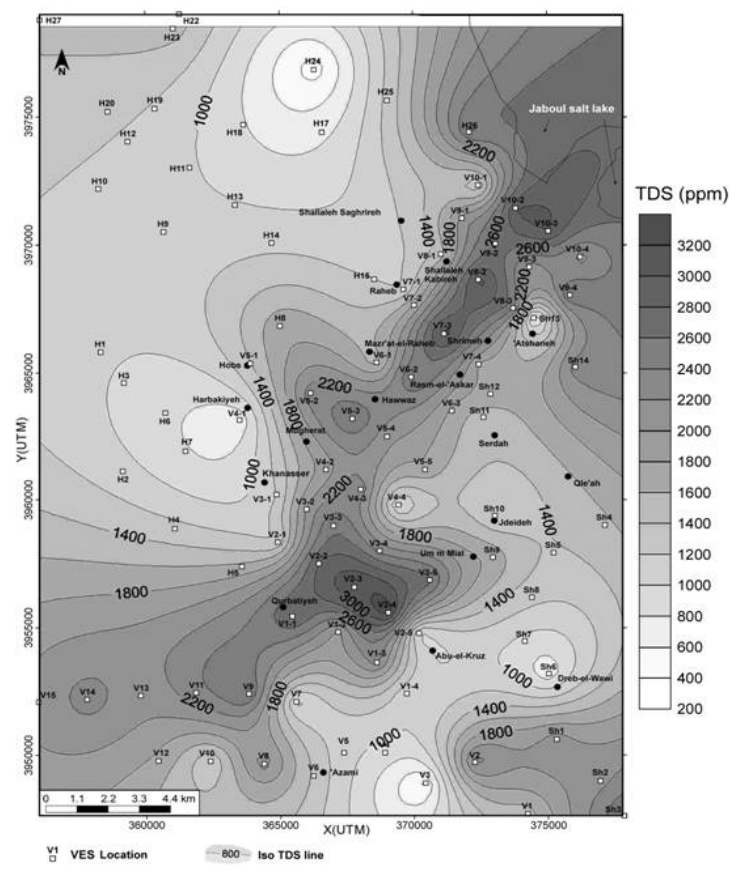

b)

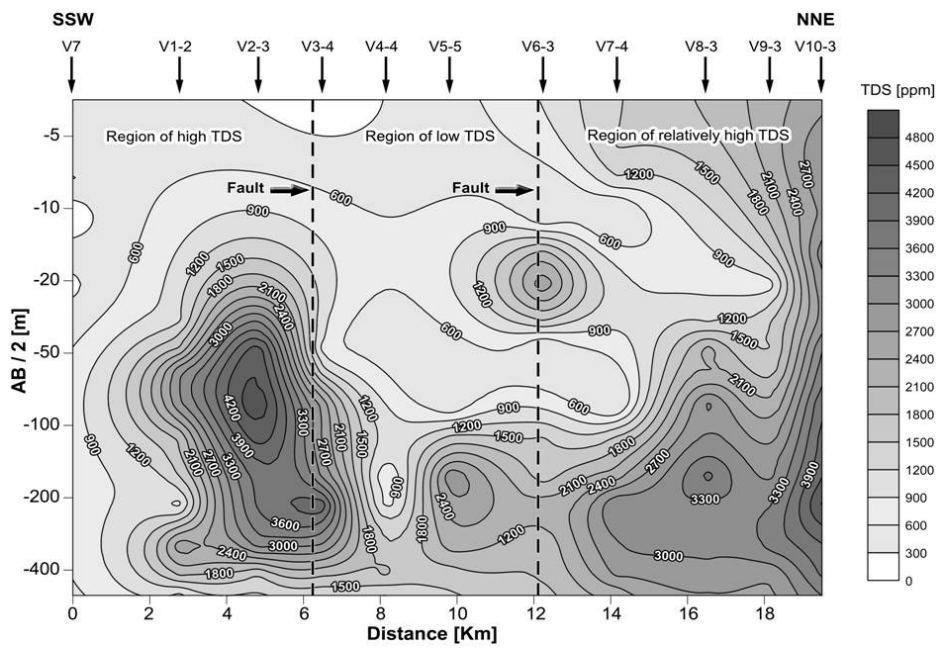

Fig. 8. (a) Salinity map for a constant $A B / 2$ of $100 \mathrm{~m}$ in the Khanasser valley (Asfahani, $200 \%$ c); (b) Salinity map as a function of $A B / 2$ along $L P 3$ in the Khanasser valley (Asfahani, 2010b). 
variations in space along the longitudinal profiles $L P 1, L P 2, L P 3$ were established through converting depth quantitative interpretative models into different groundwater areas (Asfahani, 200\%c; Asfahani, 2010b). Fig. 9 shows the distribution of those different zones obtained through integrating the results obtained for $L P 1, L P 2$, and $L P 3$ in the Khanasser valley. The depths of interface between different water zones were determined, that must be used for proper ground-water management.

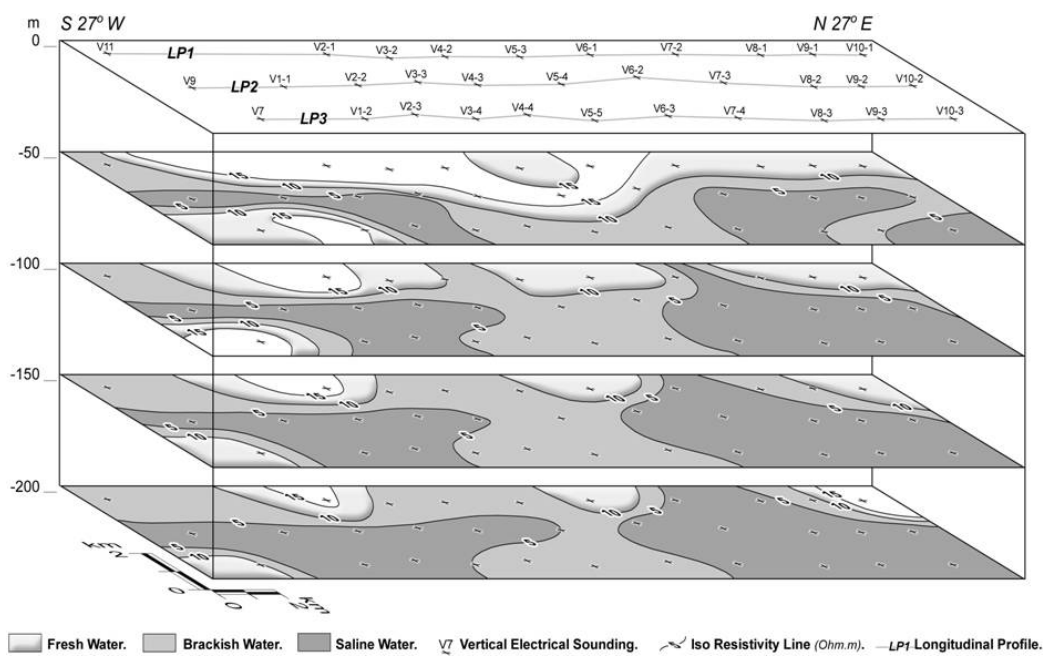

Fig. 9. Several water zones along $L p 1, L p 2$, and $L p 3$ in the study Khanasser valley region (Asfahani, 2010b).

4) The salt water intrusion signalled in the northern part of the Khanasser valley has been also taken into consideration and studied in more details through interpreting and analyzing the profile $(P r-1)$ of $8.67 \mathrm{~km}$ long and of NE-SW direction. Aditional VES measurements called VB1 to VB15 have been carried out at the north of Hobs-Serdah water divide line for this intrusion purposes as shown in Fig. 10a, (Asfahani and Abou Za$k h e m, 2013)$. RES2DINV program is used to interpret the raw resistivity data of nine VES distributed along $\operatorname{Pr}$-1, and to obtain the 2D inverted resistivity model as shown in Fig. 10b. The inverted model with rms of $4.9 \%$ is obtained after 5 iterations, where a real penetration depth of $80 \mathrm{~m}$ is reached for the lithological section corresponding for $A B / 2$ from 
3 to $200 \mathrm{~m}$. The RES2DINV results obtained along the analyzed Pr-1 are in an acceptable agreement with those obtained by traditional VES interpretations discussed in this paper. The evaluated TDS values computed for different $A B / 2$ spacings by applying the constructed empirical relationship (3) (Asfahani, 200\%c) between the interpreted earth resistivity and TDS concentration were traced along the $P r-1$ as a function of the $A B / 2$ spacings (Fig. 10c). The arrows shown in Fig. 10c indicate obviously to the salt water propagation, reaching the surface at the VB5 location, where the contact between saline and brackish water is drawn.

Fig. 10c shows a supposed movement of saline groundwater from Jaboul salt lake towards the south, as a result of the intensive pumping and a subsequent lowering of the groundwater table. The fact that there was a groundwater divide in the middle of the valley between Atshaneh and Rasm Asker in the first half of May 2002, when pumping was still going on cannot sustain a groundwater flow caused by a hydraulic gradient towards the southern region. The salts could actually moves towards the hydraulic divide line in the form of a dense saline layer moving southward in the lower Eocene and Quaternary, where the surface of this formation was dipping to the south direction and the leakage factor of the old lake or periodical transgressions during the wet season permitted the intrusion of salt water (Hoogeveen and Zobisch, 1999).

The general trends of the intrusion phenomenon discussed above are also shown on the constructed geoelectrical lithological section of $\operatorname{Pr}-1$, where three zones of groundwater quality are depicted (Fig. 10d). These zones are fresh water $(\rho e>10 \Omega \mathrm{m})$, brackish ( $\rho$ e between 5 and $10 \Omega \mathrm{m}$ ) and saline groundwater $(\rho e<5 \Omega \mathrm{m}$ ). The interfaces existing between those different water zones are also traced, where a large extension of the brackish water is observed, indicating almost its dominance along this $\operatorname{Pr}$-1 section. A remarkable low-resistive anomaly, reaching the surface, is also depicted at the VB5 location, where the well 97 of a depth of $40 \mathrm{~m}$ is located. This resistivity anomaly may indicate a probable saline groundwater up-coning through Quaternary deposits resulting from the intense fresh water pumping. The excessive fresh-water depletion affects therefore largely the groundwater quality by upward of deep flow of saline water, that should be necessarily avoided. It is therefore required to monitor and keep the fresh-salt water interface in a stationary situa- 
a)

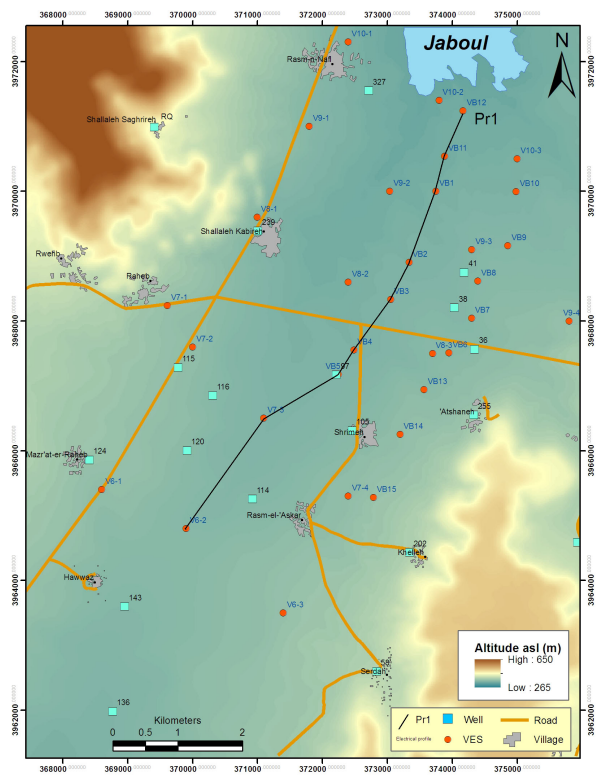

b)
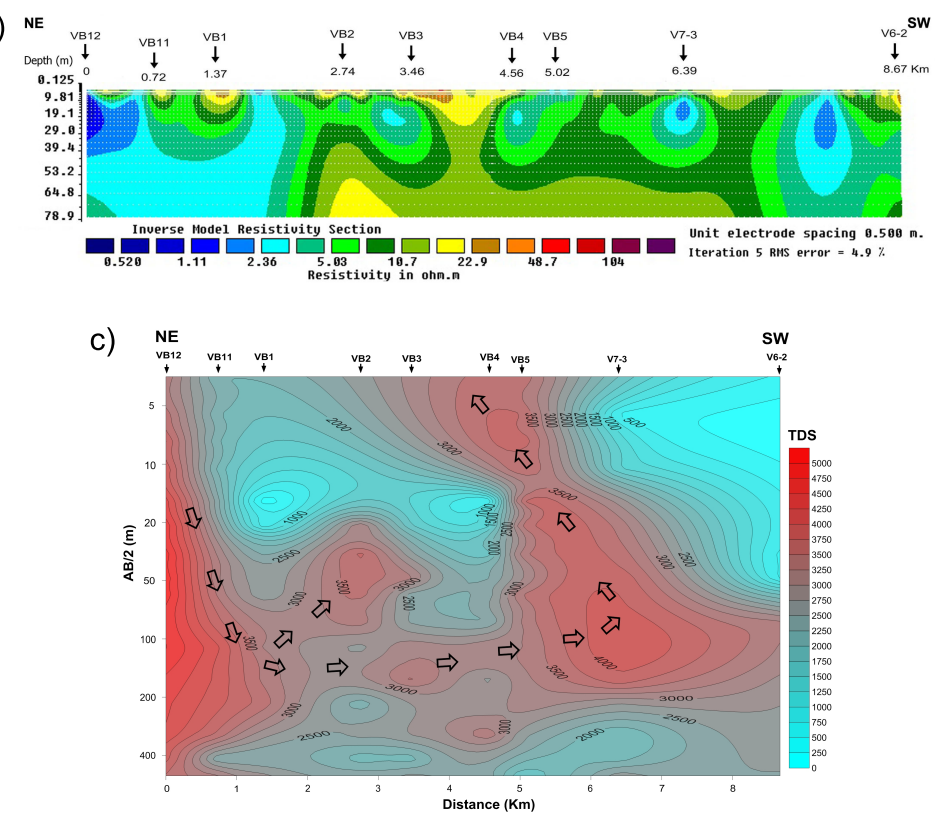

Continued on the next page. 
d)

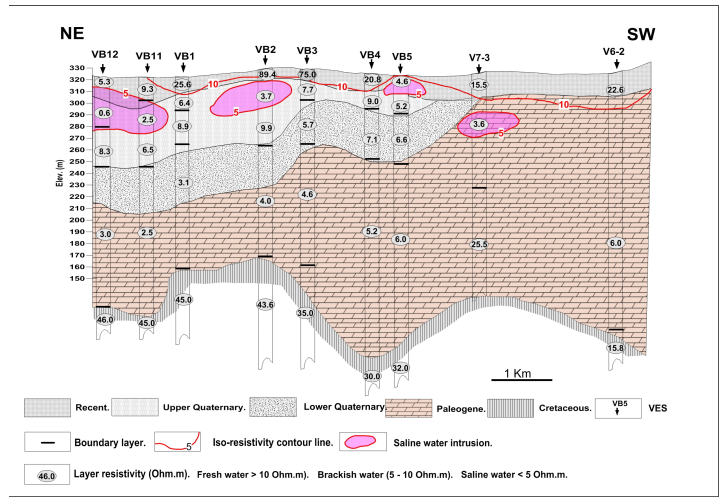

Fig. 10. (a) Location of $P r-1$ used for intrusion characterization in the Khanasser valley (Asfahani and Abou Zakhem, 2013); (b) 2D inverted resistivity model along Pr-1 (Asfahani and Abou Zakhem, 2013); (c) TDS salinity map as a function of $A B / 2$ along Pr-1 (Asfahani and Abou Zakhem, 2013); (d) General intrusion trends observed along established geoelectrical Pr-1 section (Asfahani and Abou Zakhem, 2013).

tion by pumping a limited amount of groundwater, and this depends on the available fresh water and the water balance in the region.

5) Azimuthal directional VES technique is practiced in this research project to delineate the groundwater flow directions in the Quaternary and Paleogene aquifers in the Khanasser valley region.

The apparent resistivity in the directional VES technique is measured for several directions through rotating an electrode array about its centre. Using this adapted effective technique, it is easy to determine the principal directions anisotropy, related directly to structural or lateral lithological changes in the subsurface (Massoud et al., 2009; Taylor and Fleming, 1988). The anisotropy is generally caused by the presence of fluid-filled fractures in a relatively resistive rock or soil.

Standard Schlumberger configuration is used to conduct three azimuthal resistivity soundings V6-3, V2-3, and V8-2 in the Khanasser valley along the azimuths of $0,45,90$, and 135 .

Resistivity values for different $A B / 2$ spacings in V2-3 have been plotted on a polar diagram as shown in Fig. 11. The sedimentological nature of the Quaternary aquifer composed of proluvial, alluvial and lacustrine deposits is responsible on the provocation and the creation of the ob- 
served anisotropy. It has been found for the three studied polar VES (V6-3, V2-3, and V8-2) a positive tendency between the transmissivity of the saturated Quaternary aquifer and the ratio of $\rho_{\min } / \rho_{\max }$ (ratio of small apparent resistivity to the big apparent resistivity), for different $A B / 2$ (Asfahani, 2013). The principal directions of groundwater flow are presented by the direction of $\rho_{\max }$ in the polar resistivity diagrams, as shown in Table 1.

Table 1. Principal directions of groundwater flow for different $A B / 2$ in VES (2-3, 6-3, and 8-2).

\begin{tabular}{|c|c|c|}
\hline VES No. & $\boldsymbol{A B / 2}(\mathbf{m})$ & $\begin{array}{c}\text { Principal directions } \\
\text { of groundwater flow }\end{array}$ \\
\hline VES 2-3 & from $15 \mathrm{~m}$ to $500 \mathrm{~m}$ & NE-SW \\
\hline VES 6-3 & from $5 \mathrm{~m}$ to $50 \mathrm{~m}$ & N-S \\
\hline & from $70 \mathrm{~m}$ to $500 \mathrm{~m}$ & N-S \\
\hline VES 8-2 & from $5 \mathrm{~m}$ to $40 \mathrm{~m}$ & E-W \\
\hline & from $50 \mathrm{~m}$ to $200 \mathrm{~m}$ & NE-SW \\
\hline & from $300 \mathrm{~m}$ to $500 \mathrm{~m}$ & \\
\hline
\end{tabular}

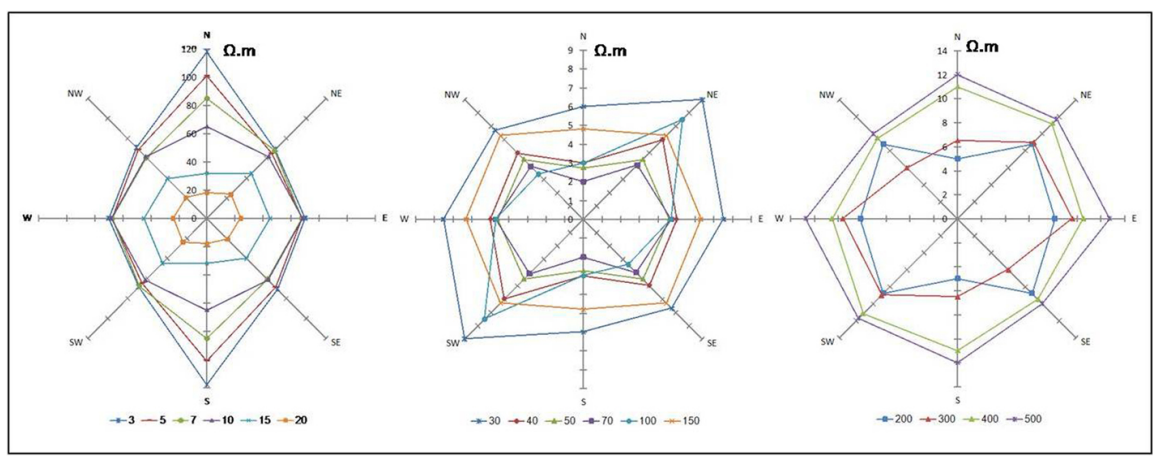

Fig. 11. Polar resistivity diagrams for different $A B / 2$ in the VES 2-3 (Asfahani, 2013).

6) Two different purely alternative geoelectrical approaches have been developed, tested and applied during this integrated research project in the Khanasser valley region. They are designed for deriving and estimating the hydraulic parameters of hydraulic conductivity and transmissivity of both the Quaternary and Paleogene aquifers in the Khanasser valley.

The first alternative methodology takes the clay effect into account, where the hydraulic conductivity in the interpreted calibrated VES locations is firstly estimated by the use of Kozeny-Carman-Bear equation 
(Bear, 1972). Calibrated VES soundings in this geoelectrical alternative technique are measured at the vicinity, where water samples taken from known depth of Quaternary aquifer are available. The transmissivity of the Quaternary in the Khanasser Valley is thereafter evaluated for those calibrated VES. A calibrated relation (3) between transverse resistance $T R$ ( $T R$ is the product of the aquifer saturated thickness and its resistivity) and transmissivity $T$ is consequently constructed, (Asfahani, 2012, 2013). This calibration relation permits thereafter to easily obtain the transmissivity and the hydraulic conductivity, even in the VES locations where no water samples exist.

The calibration relation constructed between $T R$ and $T$ has the following form (Asfahani, 2012):

$T R=5.758{ }^{*} T^{1.015}$,

with $R^{2}$ of 0.736 .

According to the clay geoelectrical alternative approach, the transmissivity of the Quaternary aquifer in the Khanasser Valley attains its maximum of $131.6 \mathrm{~m}^{2} /$ day (Fig. 12a).

The transmissivity of the Paleogene aquifer is also estimated by adapting an average hydraulic conductivity $(K)$ of $0.0054 \mathrm{~m} /$ day (Asfahani, 2013). The low productivity characterizes the Paleogene aquifer. Its transmissivity value varies between a minimum of $0.31 \mathrm{~m}^{2} /$ day observed at V2-3, and a maximum of $1.54 \mathrm{~m}^{2}$ /day observed at V4-3, with an average of $0.94 \mathrm{~m}^{2} /$ day as indicated in Fig. 12b (Asfahani, 2013). It has been well noticed many differences in hydrogeological characteristics between the north and the south of the Hobs-Serdah dividing line, already delineated by Asfahani (2007b). A distinct relatively transmissive structure is observed at the south of this line, whereas the transmissivity is more complicated toward the north.

The second alternative geoelectrical methodology takes only the salinity of the groundwater into account (Asfahani, 2016). According to this approach, VES are firstly measured in the locations, where water samples are available. Empirical relationships between transverse resistance Dar-Zarrouck $T R$ and modified transverse resistance $M T R$, and between $M T R$ and transmissivity $T$ are consequently constructed and calibrated for those VES points as follows: 
$M T R=2.017^{*} T R-91.84$,

with $R^{2}$ of 0.691 , and correlation coefficient of 0.83 , and

$T=0.239^{*} M T R+153.9$,

with $R^{2}$ of 0.641 , and correlation coefficient of 0.80 .

Those two relationships (4) and (5) are thereafter applied and used to extrapolate and evaluate the transmissivity even in the VES points where no water samples exist. An acceptable agreement is noticed between the hydraulic conductivity values obtained by this alternative technique and those obtained by the four pumping tests, where those values range between 0.864 and $8.64 \mathrm{~m} /$ day $\left(10^{-5}\right.$ and $\left.10^{-4} \mathrm{~m} / \mathrm{s}\right)$. Fig. $12 \mathrm{c}$ shows the transmissivity distribution and hydraulic conductivity of the Quaternary Khanasser valley. It is shown that the transmissivity obtained by the salinity groundwater approach varies between a minimum of $79 \mathrm{~m}^{2} /$ day and a maximum of $814 \mathrm{~m}^{2} /$ day, with an average of $283 \mathrm{~m}^{2} /$ day and a standard deviation of $145 \mathrm{~m}^{2} /$ day. The average hydraulic conductivity of $13.8 \mathrm{~m} /$ day obtained by this second approach is overestimated in comparison with that obtained by the first alternative clay approach $(2.23 \mathrm{~m} /$ day $)$. This comparison between the two different developed approaches indicates to the importance of the clay effect, that must be taken into account. The presence of the clay considerably decreases the hydraulic conductivity of the studied aquifer, as it was demonstrated through the analysis of the Quaternary aquifer in the Khanasser valley region.

Finally, the present case study of Khanasser valley allows us to shows on a real field example how the geoelectrical survey can largely contribute in solving different hydrogeological problems in semi arid regions. The influences and interactions between the different hydrogeological constraints of the Quaternary and Paleogene aquifers in the Khanasser valley have been well discussed in this general review paper with a very detailed analysis. The salinity distributions and its variations in the Khanasser valley have been clarified through characterizing the two northern and southern hydrological structures delineated by Asfahani (2007b).

The role of the geoelectrical surveys in characterizing and deriving the 

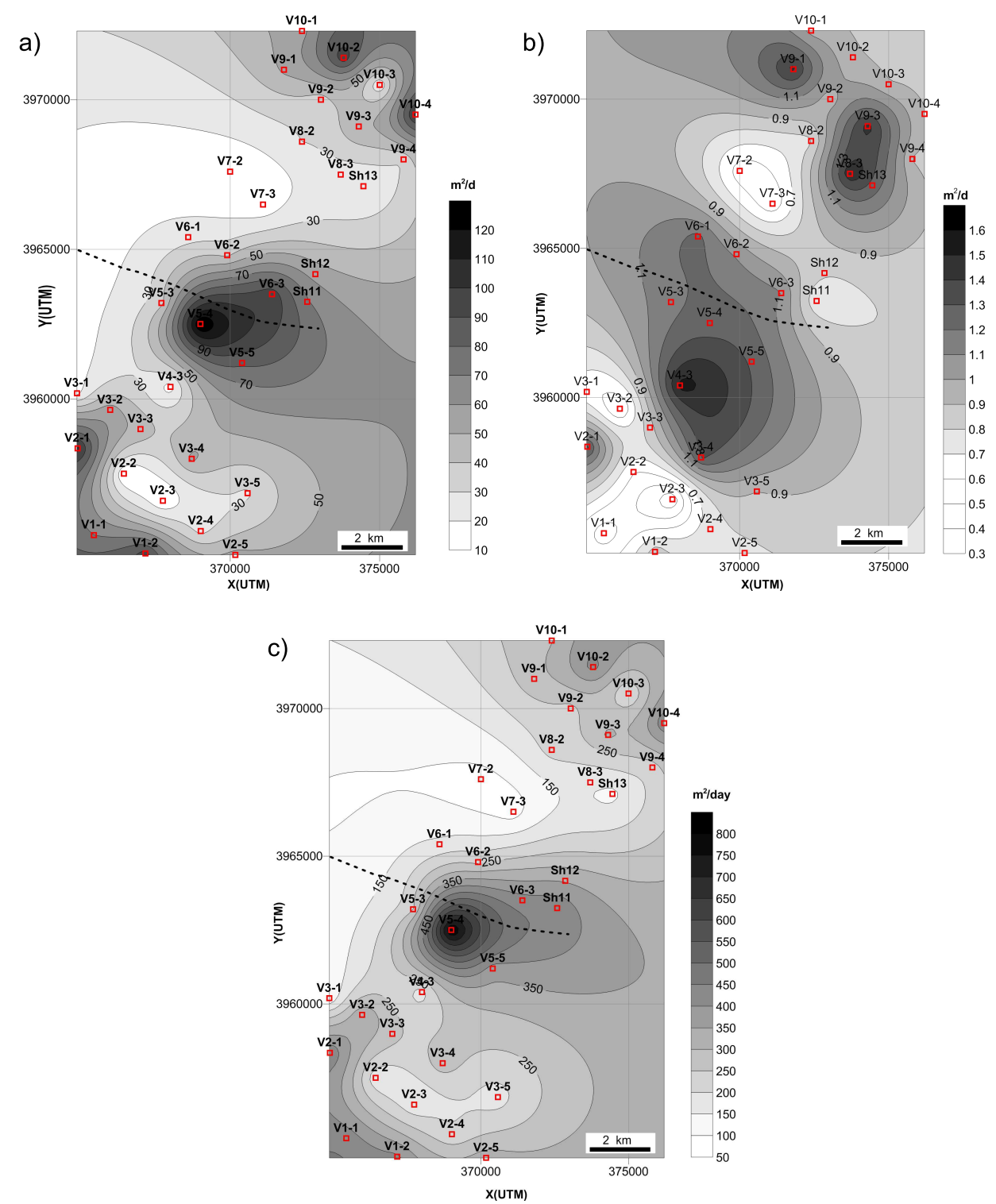

Fig. 12. (a) Established Quaternary aquifer transmisivity map derived by clay alternative approach in the Khanasser valley (Asfahani, 2013); (b) Established Paleogene aquifer transmisivity map in the Khanasser valley (Asfahani, 2013); (c) Established Quaternary aquifer transmisivity map derived by salinity alternative approach in the Khanasser valley (Asfahani, 2016). 
hydrogeological conditions in semi arid Khanasser valley region in Syria has been proven. The cost of those surveys is relatively cheap, and their applications efficacy give rapidly important subsurface hydrological results. Those obtained results could be essentially required for future research managements and developments in the study region.

\section{Conclusion}

This general review paper describes and summarizes the main integrated following results that we have already obtained during the geophysical research project, carried out in the Khanasser valley:

1) The geometrical and electrical characteristics of both Quaternary and Paleogene aquifers in the Khanasser valley region have been well delineated. The depth to the top of Maestrichtian is also estimated. The subsurface basalt distributions in Jable Al-Hess in the west and Jable Shbaith in the east have been also characterized through interpreting the VES measurements, executed on those two Jables.

2) The iso resistivity lines obtained for all $A B / 2$ spacings indicate the presence of two different hydrogeological structures, separated by HobsSerdah water divide line. Those structures have their specific influences on thicknesses, resistivity, salinity, intrusion, hydraulic conductivity, and transmissivity of both Quaternary and Paleogene aquifers.

3) The boundaries of buried paleosabkha have been well delineated.

4) All the tectonic features with the fractured zones have been delineated in the Khanasser valley region.

5) The intrusion phenomenon in the study region has been well discussed and documented.

6) Two alternative geoelectrical approaches have been developed, tested and successively practiced for estimating the hydraulic conductivity and the transmissivity of Quaternary and Paleogene aquifers in the Khanasser valley region. The first one takes the clay effect into consideration, while the second one takes only the salinity of groundwater into account. Their applications in the study region give convincible and reasonable results in comparing with the results obtained by pumping tests. 
7) The role of geoelectrical surveys in characterizing and deriving the constraints and hydrogeological conditions in studying the semi arid regions is clarified through the present case study of Khanasser Valley region in Syria.

The geophysical information presented in this review paper is important, and could be regarded as a basic document for future advanced hydrological studies. All the different approaches developed in this geophysical research have been successfully applied in the semi arid Khanasser valley, and could be recommended for other similar worldwide areas.

Acknowledgements. Author would like to thank Dr. I. Othman, General Director of Atomic Energy Commission of Syria for allowing this integrated geoelectrical research results to be published. The German Ministry of Economic Cooperation and Development (BMZ) and German Agency for Technical Cooperation (GTZ) are acknowledged for financial and administrative support to the Khanasser Valley Integrated Research Site (KVIRS) project. Late Professor. Rieser Armins (coordinator of the project) from Bonn university, Germany is deeply thanked for many useful discussions during the preparation stages of this project. ICARDA is highly thanked for providing the facilities and the logistics during the realization of Khanasser Valley project. The anonymous reviewers are thanked for their critics and remarks that improved the final version of this paper. Dr. Igor Kohut, the editor of Contribution to Geophysics and Geodesy Journal is cordially thanked for his editing and collaboration with the author during the different stages of this publication.

\section{References}

ACSAD, 1984: Water Resources Map of the Arab Countries, The Arab Center for the Studies of Arid Zones and Dry Lands, Damascus, Syria.

Arétouyap Z., Nouayou R., Njandjock Nouck P., Asfahani J., 2015: Aquifers productivity in the Pan-African context. Journal of Earth System Science, 124, 3, 527-539.

Arétouyap Z., Njandjock Nouck P., Nouayou R., Assatse W. T., Asfahani J., 2017: Aquifer porosity in the Pan-African semi-arid context. Environ. Earth Sci., 76, 3, 134, doi : 10.1007/s12665-017-6440-0.

Arétouyap Z., Bisso D., Njandjock Nouck P., Amougou Menkpa L. E., Asfahani J., 2018: Hydrogeophysical Characteristics of Pan-African Aquifer Specified Through an Alternative Approach Based on the Interpretation of Vertical Electrical Sounding Data in the Adamawa Region, Central Africa. Natural Resources Research, 28, 1, 63-77, https://doi.org/10.1007/s11053-018-9373-8. 
Asfahani J., 2007a: Neogene aquifer properties specified through the interpretation of electrical sounding data, Sallamiyeh region, central Syria. Hydrol. Process, 21, 2934-2943, doi : 10.1002/hyp.6510.

Asfahani J., 2007b: Geoelectrical investigation for characterizing the hydrogeological conditions in semi-arid region in Khanasser valley, Syria. J. Arid. Environ., 68, 31-52, doi: $10.1016 / j$.jaridenv .2006.03.028.

Asfahani J., 2007c: Electrical earth resistivity surveying for delineating the characteristics of ground water in semi arid region in Khanaser Valley, Northern Syria. Hydrol. Process, 21, 1085-1097, doi : 10.1002/hyp.6290.

Asfahani J., Radwan Y., 2007: Tectonic Evolution and Hydrogeological Characteristics of Khanasser Valley, Northern Syria, Derived from the Interpretation of Vertical Electrical Soundings. Pure Appl. Geophys., 164, 2291-2311, doi: 10.1007/s00024 -007-0274-8.

Asfahani J., 2010a: Application of surfacial geoelectrical resistivity technique in hydrogeology domain for characterizing saline groundwater in semi arid regions. In: Benjamin Veress, Jozsi Szigethy (Eds.), Horizons in earth science research series. NOVA Science Publishers, New York, 1, 351-381.

Asfahani J., 2010b: Electrresistivity investigations for guiding and controlling fresh water well drilling in semi arid region in Khanasser Valley, Northern Syria. Acta Geophys., 59, 1, 139-154, doi: 10.2478/s11600-010-0031-8.

Asfahani J., 2012: Quaternary aquifer transmissivity in semi arid region in Khanasser valley, Northern Syria. Acta Geophys., 60, 4, 1143-1158, doi: 10.2478/s11600-012-0 $016-\mathrm{x}$.

Asfahani J., 2013: Groundwater potential estimation deduced from vertical electrical sounding measurements in the semi-arid Khanasser valley region, Syria. Hydrol. Sci. J., 58, 2, 468-482, doi: 10.1080/02626667.2012.751109.

Asfahani J., Abou Zakhem B., 2013: Geoelectrical and hydrochemical investigations for characterizing the salt water intrusion in the Khanasser valley, northern Syria. Acta Geophys., 61, 2, 422-444, doi: 10.2478/s11600-012-0071-3.

Asfahani J., 2016: Hydraulic parameters estimation by using an approach based on vertical electrical soundings (VES) in the semi-arid Khanasser valley region, Syria. J. Afr. Earth. Sci., 117, 196-206, doi: 10.1016/j.jafrearsci.2016.01.018.

Attwa M., Günther T., Grinat M., Binot F., 2009: Transmissivity estimation from sounding data of Holocene tidal flat deposits in the north eastern part of Cuxhaven, Germany. Extended abstracts, Near Surface 2009: 15th European Meeting of Environmental and Engineering Geophysics, Dublin, Ireland, 7-9 September, 2009, P29 (Sub ID: 6710).

Bear J., 1972: Dynamics of fluids in porous media. Elsevier, New York.

Chandra S., Ahmed S., Ram A., Dewandel B., 2008: Estimation of hard rock aquifer hydraulic conductivity from geoelectrical measurements: a theoretical development with field application. J. Hydrol., 357, 218-227, doi : 10.1016/j.jhydrol. 2008.05 .023 . 
Chandra S., Dewandel B., Dutta S., Ahmed S., 2010: Geophysical model of geological discontinuities in a granitic aquifer: analyzing small-scale variability of electrical resistivity for groundwater occurrences. J. Arid. Geophys., 71, 4, 137-148, doi: 10.1016/j.jappgeo.2010.06.003.

Dobrin M. B., 1976: Introduction to Geophysical Prospecting. McGraw-Hill, New York.

Eleraki M., Gadallah M., Gemail K., Attwa M., 2010: Application of resistivity method in environmental study of the appearance of soil water in the central part of Tenth of Ramadan City, Egypt. Q. J. Eng. Geol. Hydrol., 43, 171-184.

Heigold P. C., Gilkeson R. H., Cartwright K., Reed P. C., 1979: Aquifer transmissivity from sacrificial electrical methods. Ground Water, 17, 4, 338-345.

Hoogeveen R. J. A., Zobisch M., 1999: Decline of groundwater quality in Khanasser valley (Syria) due to saltwater intrusion. Paper presented at the International Dryland Conference, Cairo, Egypt, August, 16 pp.

Jaworska-Szule B., 2009: Groundwater flow modelling of multi aquifer systems for regional resources evaluation: The Gdansk hydrogeological system, Poland. Hydrogeology Journal, 17, 1521-1542.

Kazakis N., Vargemezis G., Voudouris K., 2016: Estimation of hydraulic parameters in a complex porous aquifer system using geoelectrical methods. Sci. Total Environ., 550, 742-750.

Kelly W. E., 1977: Geoelectrical sounding for predicting aquifer properties. Ground Water, 15, 420-425.

Khalil M. H., 2012: Reconnaissance of freshwater conditions in a coastal aquifer: synthesis of 1D geoelectric resistivity inversion and geohydrological analysis. Near Surf. Geophys., 10, 427-441.

Massoud U., El Qady G., Metwaly M., Santos F., 2009: Delineation of shallow subsurface structure by azimuthal resistivity sounding and joint inversion of VES TEM data: case study near Lake Qaroun, El Fayoum, Egypt. Pure and Applied Geophysics, 166, 701-719.

Massoud U., Santos F. M., Khalil M. A., Taha A., Abbas M. A., 2010: Estimation of aquifer hydraulic parameters from surface geophysical measurements: a case study of the Upper Cretaceous aquifer, central Sinai. Egypt Hydro. J., 18, 699-710.

Metwaly M., Elawadi E., Moustafal S. S. R., Al Fouzan F., Mogren S., Al Arifi N., 2012: Groundwater exploration using geoelectrical resistivity technique at Al-Quwy'yia area central Saudi Arabia. Int. J. Phys. Sci. 7, 2, 317-326.

Niwas S., Singhal D. C., 1981: Estimation of aquifer transmissivity from Dar-Zarrouk parameters in porous media. J. Hydrol., 50, 393-399.

Niwas S., Singhal D. C., 1985: Aquifer transmissivity of porous media from resistivity data. J. Hydrol., 82, 143-153.

Niwas S., Tezkan B., Israil M., 2011: Aquifer hydraulic conductivity estimation from surface geoelectrical measurements for Krauthausen test site, Germany. Hydrogeol. J., 19, 307-315.

Niwas S., Celik M., 2012: Equation estimation of porosity and hydraulic conductivity of Ruhrtal aquifer in Germany using near surface geophysics. J. Appl. Geophys., 84, $77-85$. 
Orellana E., Mooney H. M., 1966: Master tables and curves for vertical electrical sounding over layered structures, interciencia, Madrid, Spain.

Pichgin N. I., Habibullaev I. K. H., 1985: Methodological recommendations in studying geo-tectonic conditions of vertical electrical soundings data with application of EC computer for solving hydrogeological and geoengineering problems. Tashkend (in Russian).

Ponikarov V. P., 1964: The Geological Map of Syria, 1:200000 and Explanatory Notes. Syrian Arab Republic, Ministry of Industry, Department of Geological and Mineral Research, Damascus, Syria.

Purvance D., Andricevic R., 2000: Geoelectrical characterization of the hydraulic conductivity field and its spatial structure at variable scales. Water Resour. Res., 36, $10,2915-2924$.

Skinner D., Heinson G., 2004: A comparison of electrical and electromagnetic methods for the detection of hydraulic pathways in a fractured rock aquifer, Clare Valley, South Australia. Hydrogeol. J., 2. 576-590.

Soumi G., 1991: Supplemental Irrigation Systems of the Syrian Arab Republic (SAR). In: Proceeding of the Workshop on Regional Consultation on Supplemental Irrigation. ICARDA and FAO, 7-9 December 1987, Rabat, Morocco. Kluwer Academic Publishers, Dordrecht, The Netherlands, pp. 497-511.

Soupios P., Kouli M., Vallianatos F., Vafidis A., Stavroulakis G., 2007: Estimation of aquifer hydraulic parameters from surficial geophysical methods: a case study of Keritis Basin in Crete. J. Hydrol., 338, 122-131.

Takhur J. K., 2016: Hydrogeological modelling for improving groundwater monitoring network and strategies. Applied Water Sciences, 1-18.

Taylor R. W., Fleming A. H., 1988: Characterizing jointed systems by azimuthal resistivity surveys. Ground Water, 26, 464-474.

Tizro A. T., Kostantanous S., Voudouris K., Salehzade M., Mashayekhi H., 2010: Hydrogeological framework and estimation of aquifer hydraulic parameters using geoelectrical data: a case study from West Iran. Hydrogeology Journal, 18, 917-929.

Tizro A. T., Voudouris K., Basami Y., 2012: Estimation of porosity and specific yield by application of geoelectrical method - A case study in western Iran. Journal of Hydrology, 454-455, 160-172.

Wolfahrt R., 1966: Zur Hydrologie vor Syrien. Bundesanstalt für Bodenforschung und den Geologischen Landesämtern der Bundesrepublik Deutschland (in German).

Wolfahrt R., 1967: Geologie von Syrien und Lebanon, Gebrüder Bornträger, BerlinNikolasee (in German).

Zohdy A. A. R., 1989: A new method for the automatic interpretation of Schlumberger and Wenner sounding curves. Geophysics, 54, 245-253.

Zohdy A. A. R., Bisdorf R. J., 1989: Schlumberger Sounding Data Processing and Interpretation Program, US Geological Survey, Denver. 